\title{
Death anxiety among psychiatry trainees during COVID-19
}

\author{
Aisha Sanober Chachar, MBBS, FCPS (Psych)
}

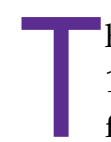
he coronavirus disease 2019 (COVID19) pandemic has evoked extreme fear at a collective level. In the current health care climate of quick fixes and high-acuity workloads, there is a potential to value efficiency over the process. Such demands can endanger clinicians' internal emotional needs, create conflicts, and potentially impact their relationships with patients and families. What does this mean for a psychiatry trainee? Here I share some insights about death anxiety, and how psychiatry training promotes self-reflection, which shapes our relationship with death.

\section{The far-reaching effects of death anxiety}

Postgraduate psychiatry training may expose one to stressful situations with adverse psychologic consequences. ${ }^{1}$ Furthermore, when caring for patients, psychiatry trainees frequently need to face issues of death and dying in the form of suicide risk assessments, grief and bereavement processes, near-death experiences, posttraumatic stress disorder, and psycho-oncology rotations. Because these interactions are incredibly personal, the emotions they provoke inevitably affect every interaction, theoretical discussion, diagnostic workup, and treatment plan.

How each of us experiences death anxiety is unique. For some, it could be a fear of nonexistence, ultimate loss, disruption of the flow of life, worry about leaving loved ones behind, or fear of pain or loneliness

in dying. Some might fear an untimely or violent death and subsequent judgment and retributions. The literature suggests that fear of death may be at the root of various mental health problems and, if left unaddressed, may adversely impact longterm treatment outcomes. ${ }^{2}$ Despite this, many standard treatment approaches typically do not target death anxiety, which potentially contributes to a "revolving door" of mental health problems. ${ }^{3}$

American existential psychiatrist Irvin Yalom, MD, cautioned psychiatrists not to "scratch where it does not itch." ${ }^{4}$ Yet death, according to Dr. Yalom, does itch. Violent death is that caused by human intent or negligence, and is characterized by feeling helpless and terrorized at the time of dying. It may occur as an acute incident that denies the dying individual and his/ her family members the time and space to prepare for the death. ${ }^{5}$ For survivors, accommodating the mental, emotional, psychological, and spiritual effects of violent death is a complex process that rarely has a conclusion. It often is accompanied by survivors' guilt, which is replayed in the form of flashbacks and nightmares. ${ }^{6}$ With this understanding, I view COVID-19 deaths as violent deaths.

continued

LET YOUR VOICE BE HEARD

CURRENT PSYCHIATRY invites psychiatry residents to share their views on professional or clinical topics for publication in Residents' Voices. E-mail jbauer@mdedge.com for author guidelines.

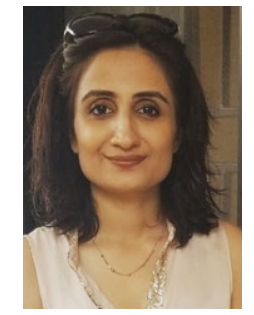

Dr. Chachar is a Clinical Fellow, Child \& Adolescent Psychiatry, Aga Khan University, Karachi, Pakistan, and Consultant Child \& Adolescent Psychiatrist and Medical Director, Alleviate Addiction Suffering (AAS) Trust, Pakistan.

Disclosure

The author reports no financial relationships with any companies whose products are mentioned in this article, or with manufacturers of competing products.

doi: $10.12788 / c p .0070$ 
Clinical Point

\section{It is our ethical and moral responsibility towards our patients to listen to our countertransference responses}

\section{Pay close attention to countertransference}

As much as we influence our patients and their families, we also are profoundly influenced by them. We need to pay attention to any feelings our clinical encounters generate within us, and to carefully use these feelings in our clinical judgment, and not just make causal inferences. For instance, if a clinician thinks that a patient with suicidal ideation would be better off dead, these feelings are a reliable indicator that the patient is, indeed, at a high risk of completing suicide. ${ }^{7}$ It is our ethical and moral responsibility towards our patients to listen to our countertransference responses. The aim is to identify countertransference and use it to inform us, not to rule us. By taking an active role in managing our emotional responses in the face of loss, we can harness the spirit of resilience. This is not always as easy as it seems. We need our peers, experienced clinicians, and supervisors to help us explore our feelings, resistances, and countertransference reactions.

\section{Strategies to combat burnout}

Psychiatric trainees must be encouraged to establish and maintain rigorous plans of self-care to prevent compassion fatigue and burnout. Most importantly, training programs must diversify residents' clinical exposure by providing activities that promote mental health promotion activities, scholarly endeavors, and peer support groups. This will help trainees to restore meaning and purpose in life beyond.

References

1. Coverdale I, Balon R, Beresin EV, et al. What are some stressful adversities in psychiatry residency training, and how should they be managed professionally? Acad Psychiatry. 2019;43(2):145-150

2. Russac RJ, Gatliff C, Reece M, et al. Death anxiety across the adult years: an examination of age and gender effects. Death Stud. 2007;31(6):549-561.

3. Lisa I, Menzies RG, Menzies RE. Death anxiety and its role in psychopathology: reviewing the status of a transdiagnostic construct. Clinical Psychology Review. 2014;34(7):580-593.

4. Yalom ID. Staring at the sun: being at peace with your own mortality. London, UK: Piatkus; 2011.

5. Rynearson EK, Johnson TA, Correa F. The horror and helplessness of violent death. In: Katz RS, Johnson TA (eds). When professionals weep: emotional and countertransference responses in palliative and end-of-life care. Abingdon, UK: Routledge; 2016:91-103.

6. Breggin PR. Guilt, shame, and anxiety: understanding and overcoming negative emotions. Buffalo, NY: Prometheus Books; 2014.

7. Katz RS, Johnson TA, (eds). When professionals weep: Emotional and countertransference responses in palliative and end-of-life care. Abingdon, UK: Routledge; 2016.
Discuss this article at www.facebook.com/ MDedgePsychiatry 